\title{
Transparency or Drama? Extending the Range of Academic Writ- ing in Architecture and Design
}

Stanislav Roudavski

University of Melbourne

Faculty of Architecture, Building and Planning

\begin{abstract}
Discourses on epistemology in a variety of disciplines have established the need for diverse and casespecific approaches to writing. This need is as actual in practice-based research and the relevant fields would benefit from better support of creative experimentation with academic expression. In order to demonstrate that advances in this area are necessary, this article examines advice and criteria for writing offered by a typical writing guide. The discussed examples demonstrate that while the recommendations of such guides are useful, their emphasis on standardisation is also limiting. The article contrasts the advice common to writing guides and other prescriptive documents with the current state-of-the-art practice in qualitative research, pointing out productive alternative approaches.
\end{abstract}

\section{Keywords}

academic writing, research dissemination, creative expression, writing in creative practice, research methodology, epistemology

\section{INTRODUCTION}

This paper seeks to promote creative freedom in academic writing, and-more specifically-in academic writing that engages with qualitative characteristics of architectural designing. Its central idea is simple. When issues under consideration are complex, so can be the language that tackles them. When the subject matter is exciting or upsetting, the texts that engage with it can adapt to transmit these emotions. When an architectural project takes risks in search of an innovative outcome, the writing that seeks to extend or analyse its performance can take risks too.

These expectations do not seem controversial and yet they contrast with the bulk of current advice that seeks to regulate writing within academia. In current literature, much of this advice focuses on clarity, transparency and accessibility. Proponents of clear writing believe that academia prioritises overly complex, pretentious and obfuscating language (e.g., as reported by Keyes 2003). Their response is to campaign for simplicity and directness. Such promotion of clarity is often justified and useful. However, as Nash (2004: 69) observes, "too many 'experts' on simple, clear writing make it sound as though if you do 
not write like Ernest Hemingway or Dr. Seuss, then you are writing incorrectly, or worse, writing like an 'elitist.'”

Here is an example. A typical advice in good-writing guides is to avoid jargon (e.g., cf. Keyes 2003: 96, Luey 2010: 11). And yet, many celebrated texts are full of rare words. One of the books I have been reading recently is Richardson's A Life of Picasso (2007). Every page of this multi-volume biography contains words that make me pause. Some of these words I have never seen, some I do know but fail to recognize and others do not seem to fit their sentences. I compare their meanings in multiple dictionaries and thesauri, explore their etymologies and skim historical usage examples. I look up related words and make cards (now electronic) for rote learning.

Below, is a beautiful two-week crop, rearranged alphabetically:

...assignation, cachet, cenotaph, charette, clodpoll, colliery, coterie, countertransference, démodé, denouement, dweeb, enmity, enthymeme, ermine, excoriate, febrile, frou-frou, galumph, gueridon, haberdash, harum-scarum, hoodwink, incarcerate, inveigle, mordant, outré, pander, papier collé, pentimento, phatic, pochoir, poppycock, porcine, pouf, prima facie, proselytize, rubicund, serried, tassel, tauromachy, toady, Upanishad, vraisemblance, yoke...

To me, even when read out of context, these words are suggestive of sophisticated technical skills, exhibitionism and the bitter intrigues of the $20^{\text {th }}$-century artistic avant-garde. How can a period of such flair be described in a regulated and minimalist vocabulary? Would not the elimination of technical terms or colloquialisms deprive the text's dramatis personae of things to think, say and do?

I admit freely that this complexity can have a cost. When I encounter a text that uses many words outside of my current lexicon, reading slows down dramatically. Sometimes, I have to skim, postpone or abandon a particularly difficult piece of writing but as frequently, I find this extra challenge rewarding because it unlocks evocative power and descriptive precision unattainable by plain, functionalist language. If we recall that all language is necessarily metaphoric (Lakoff \& Johnson 1980), the ideal of simplicity, directness or transparency becomes even more problematic because a more common metaphor is also often a lifeless one. As Rorty (1989: 152) writes in his discussion of the Nabokovian worldview: "after the scales are rubbed off a butterfly's wing, you have transparency, but not beauty-formal structure without sensuous content. Once the freshness wears off the metaphor, you have plain, literal, transparent language-the sort of language which is ascribed not to any particular person but to "common sense" or "reason" or "intuition," ideas so clear and distinct you can look right through them."

My creative work and research are in the field of architecture, a discipline that is concerned with lifeworlds that subsume environments, structures, technologies and inhabitants. These lifeworlds are intrin- 
sically complex, contested and unstable. They are experienced as social dramas sometimes reaching the very ends of human capacities. All known forms and styles of representation struggle with the subjectivity, intensity and subtlety of human experience. Indeed, histories of art demonstrate that continuing formal innovation is the typical response to the overwhelmingly complex and ever-changing challenges of understanding and communicating human encounters. Architecture does include technical subfields where innovation and research can be presented with strict symbolic notations or statistical reporting. However, the focus of this paper is on architecture as a design discipline. I understand designing as a way of knowing and making that is specifically concerned with complex and unstable situations, in other words-with "wicked problems" (Buchanan 1992, Coyne 2005). When dealing with such problems, rhetorical engagement with complex and dynamic performances becomes central to the challenges of enquiry and representation.

Textual reconstructions of architectural performances are difficult but not impossible. For example, consider this brief extract describing a house not as a technical assembly of objects but as an ironic, selfconscious, and at the same time sincere evocation of a childhood experience:

I next see my mother leading me bedward through the enormous hall, where a central flight of stairs swept up and up, with nothing but hothouse-like panes of glass between the upper landing and the light green evening sky. One would lag back and shuffle and slide a little on the smooth stone floor of the hall, causing the gentle hand at the small of one's back to propel one's reluctant frame by means of indulgent pushes. Upon reaching the stairway, my custom was to get to the steps by squirming under the handrail between the newel post and the first banister. With every new summer, the process of squeezing through became more difficult; nowadays, even my ghost would get stuck. Another part of the ritual was to ascend with closed eyes. 'Step, step, step,' came my mother's voice as she led me up - and sure enough, the surface of the next tread would receive the blind child's confident foot; all one had to do was lift it a little higher than usual, so as to avoid stubbing one's toe against the riser. This slow, somewhat somnambulistic ascension in self-engendered darkness held obvious delights. The keenest of them was not knowing when the last step would come. At the top of the stairs, one's foot would be automatically lifted to the deceptive call of 'Step,' and then, with a momentary sense of exquisite panic, with a wild contraction of muscles, would sink into the phantasm of a step, padded, as it were, with the infinitely elastic stuff of its own nonexistence. (Nabokov 2000: 66)

Admittedly, this passage was written by a master whose exceptional skill, enabled by outstanding talent, matured through a life-long engagement with word craft. Most people do not have the same abilities, 
commitment or resources. Still, an encounter with such prose is educational, even if its quality is hard to match. The passage above is particularly illustrative because it attempts to resolve a challenge similar to those often encountered by writers discussing architectural environments in academia. It weaves fragmented memories of structures, spaces, people and habits into a convincing reconstruction of a meaningful place. This textual restaging of a situated experience is an extract from autobiographical prose, an inbetween genre that is not quire historical reporting and not quite fiction. Not intended as research in the academic sense, it produces an evocative effect to which some of contemporary academic writing in qualitative domains consciously aspires.

By contrast, my writing is much more formulaic. As the word sample above has likely suggested, I am not native to English. As a foreigner who began learning this language in his 20s, I am a paranoid writer. I never feel fully in control and forever hesitate over jokes, metaphors, idioms, colloquialisms, compound sentences and rare words. Even though I began recording unfamiliar English words more than 15 years ago, Gallicisms and Latinisms, technical lingo, vernacular vocabularies and contemporary slang all continue to pose problems. With this paranoia at its peak, only the assured commandments of good writing seem to promise salvation. Guide in hand, I rewrite as per the recipe: take some sentences, peel off the adverbs, chop them short, squeeze out the passives, arrange neatly and serve in small portions. Often, this shortening and purging resolves as bulleted lists. These lists are:

- concise;

- $\quad$ easy to follow; and

- deeply dissatisfying.

They have a tendency of developing a will of their own. Their logic is repelling nuances of subject matter in preference to internal harmonies. Routinely, they construct representations that barely resemble the situations they are meant to analyse and describe. Hardly helpful.

It is unfortunate that many writing guides are so single-minded because their influence is substantial. Such guides as Strunk's The Elements of Style (2000) or Williams's Style: Ten Lessons in Clarity and Grace (2002) exist in multiple editions and have been recommended to generations of writers. Sometimes, such recommendations convey an impression that this is the only correct way to do writing. For example, Luey, in the just-published $5^{\text {th }}$ edition of her Handbook for Academic Authors (Luey 2010: 4), writes that "anyone who writes should own The Elements of Style by William Strunk Jr. and E. B. White." This is the only writing-advice book that she recommends, along with a few dictionaries.

In my opinion, the guides such as these are harmful as well as beneficial. They are problematic on at least two counts. Firstly, they are too generalist. Attempting to advise the whole of academia with its diverse writing needs, they emphasise universally applicable rather than locally suitable. When the unusual is 
discouraged, innovation is stifled. Recent debates on ontology and epistemology have resulted in an increasingly influential understanding that academia is both heterogeneous and dynamic. Newer research fields, such as design disciplines, are actively experimenting with different modes of research, expression and dissemination. Creative freedom in such conditions is essential for progress. Simultaneously, typical advice on academic writing is yet to account for the consequences of the "postmodern turn" (Best \& Kellner 1997). One could say that the attitude of generalist guides on good writing is outdated. Unfortunately, as the examples below will confirm, it is far from being outmoded.

I originally began thinking about the challenges of academic writing because I wanted to improve my own textual production. However, the tension between simplicity and expressive power-or, as the title of this article puts it, between transparency and drama-is not unique to my personal struggles. On the contrary, it is a central puzzle for most academic writing on the human effects of architectural design. I feel it might be easier for me to argue for innovation and complexity because I lack the advantages of a native speaker or a literary studies specialist. When textual discourse is forced into simplistic templates, it is done in the name of struggling readers and writers. As one such reader and writer, I hereby vote for the stimulations and rewards of challenging writing in preference to the blinding comforts of conformity.

\section{TRANSPARENCY: WRITING AS REPRESENTATION}

I am not alone in wanting more from academic writing. On the contrary, the contemporary academia accommodates two distinct camps that promote startlingly different understandings of writing and manufacture authoritative literature in support of their positions. One of these camps sees writing as a predominantly representational device and the other as a method of enquiry implicated in the construction of understanding as well as a way of communicating with others.

While both of these camps are well established, the transparency group has a longer pedigree and still holds dominant positions, especially in the more stable sectors of academia, away from the recent methodological advances and speculative experimentation. Some of the important regulatory bodies, for example higher-education institutions and funding organisations have to be cautious with fashionable trends and can prudently be conservative. Operating with large sums and entrusted with producing tangible outcomes, they tend to rely on approaches approved by complex bureaucracies. Consequently, such bodies are slow in reacting to new theoretical developments, especially in the fields where the debates are still on-going. This situation is a reflection of power transactions with political implications with the most established groups typically wanting to preserve the status quo (cf. Bourdieu 1988). Power struggles in the academic discourse and marginalisation of certain groups or discourses are likely to be central to the regulation of change in academia but this discussion is beyond the scope of this article. For the present argument it is sufficient to say that while institutional caution is understandable, it is also problematic. 
For example, it is uncontroversial that design students learn better in an environment where creative experimentation is encouraged. Practical design-work in educational settings exposes them to complex problems while eliminating risks and practicalities that limit creativity. However, this beneficial atmosphere of a design studio rarely applies to writing. It is generally understood that designers need to be able to write convincingly, rigorously and critically. And yet, the standards of writing in the faculties of design and architecture are often low. Facing this situation, universities respond by manufacturing writing guides that are intended to support students' through the provision of didactic rules and standard templates.

Consider, for example, the Essay and Report Writing guide produced by the Department of Architecture at the University of Melbourne (University of Melbourne et al. 2006). Among its kin-and such guides are similar in many faculties and universities - it is a comparatively liberal and flexible specimen. Yet, its tone is frequently unequivocally authoritative and its depiction of possibilities is often simplistic and exclusionary. This article contrasts the Essay and Report Writing guide's advice with an alternative, voiced by Goodall $(2000 a, b)$ on behalf of "new ethnography". I acknowledge that this is not a straightforward likefor-like comparison. However, I believe such a comparison is valid and useful because ethnographic methods and modes of delivery discussed by Goodall seek to answer challenges that are equally important to architectural researchers.

Amongst other things, the Essay and Report Writing guide states (the emphasis in the following examples is mine):

Writing is about communicating. You may be writing an essay for study purposes, a report presenting the findings of an investigation undertaken as part of your work, or a major research thesis. Whichever is the case, writing well and clearly is essential, and you will find it even more so in your career after you have completed your studies. (p. 4)

This advice is problematic because its presupposition that "clear" writing is both attainable and best is neither sufficiently ambitious nor universally applicable. Goodall (2000: 30 2000b) observes that in addition to the traditional scholarly criteria of rigor that expected writing to be intelligent, timely, professionally competent and interesting, many researchers in ethnography now believe that writing should also be evocative, empathetic, caring, therapeutic, emotionally honest and compassionate. These additional criteria shift emphasis from the simpler challenge of writing well to the more difficult endeavour of creating shared understandings in contested and contradictory worlds.

The Essay and Report Writing guide also advises that

Your writing style is largely a personal matter, but you will be well advised to consider the guidelines offered here if you want to avoid boring, irritating or confusing your readers. (p. 5) 
This statement implies that "style" is an entity that can be detached from content and that applying this or another style is an optional and secondary concern. The conception of style as an arbitrary decoration does not work well in situations where peculiar voices of participants, including that of the writer, are essential to understanding. Objectivist, scientific epistemologies that presuppose the existence of a neutral observer are central to this understanding. Goodall (2000b) suggests that reporting of the scientific tradition is modelled on persuasive speechmaking intended to convince through logic alone. In situations where multiple logics and worldviews co-exist and are important, this mode of delivery is neither appropriate nor rigorous. Goodall's solution is to substitute the metaphor of persuasive speech with that of an enlarged conversation. This conceptual move allows him to derive criteria for writing that are more personal, narrative, dramatic and inclusive. In this kind of writing, the composition of the text is not an attribute of a writer or an optional decoration (aka style) but an exploratory device developed to suit research challenges and crafted to expose the identities of the narrators. Experimentation in qualitative research continues to extend forms of academic writing with existing examples featuring "poetry, short stories, plays, memoirs, narratives of self, performance texts, responsive readings, comedy and satire."

(Lincoln \& Denzin 2003: 375)

The subsequent extract from the Essay and Report Writing guide advises that

when you have reflected on the material and developed some organisation for the ideas and themes, you can write an outline or plan for the essay. The outline is a hierarchical way of laying out the themes of the essay. You should use the outline to set out a provisional thesis for the essay (this may evolve as you write), distinguish several themes or points to support that thesis and organize the primary and secondary sources according to these themes. An outline that gives an overview and a structure for your essay will make it much easier for you to write with direction and purpose. (p. 7)

The advice to plan before writing might seem uncontroversial because some organizational structure is necessary with most extended texts. However, the suggestion to have a ready plan before writing begins prioritizes the understanding of writing as a form of representation, implicitly suggesting that writing can be done after the work is completed and the ideas are formulated. However, this stance is incompatible with the formation of understanding in qualitative research where ideas develop through repeated encounters with situations and depend on mechanisms of participation (cf. Richardson \& Adams St. Pierre 2000). It can be even less suitable in designing where questions, problems, understandings and solutions evolve in parallel, through trial and error. Latour and others (Latour \& Woolgar 1992, Latour 1987) have demonstrated that stories told about completed artefacts can be drastically different from those that can be found in the midst of making. These stories can be better captured through writing that occurs in parallel with the events. This kind of writing emerges not as a form of representation but as a way of reflec- 
tive participation. It extends memory, slows down observation, refocuses attention, reorganizes thinking and allows the formation of otherwise unattainable insights. In short, writing can constitute a powerful method of enquiry. The rigour and explorative potential of this method can be severely undermined by pre-planned impositions. While the Guide acknowledges that early guidelines are likely to change in the process, its overall emphasis on representation in preference to exploration can encourage an understanding that sees writing as separate from the rest of the creative process. This understanding can cast writing as an artificial and boring obligation to be avoided and is certainly common among architecture students.

Another of the Guide's advices is that

it is a good principle to introduce the theme of each paragraph in the same sort of way as the theme of the whole essay - that is, to begin the paragraph by a brief statement [...] In a good essay one can often put together the first line of each paragraph to give a satisfactory précis of the whole argument. (p. 9)

Without considering alternatives or analysing implications, this very common directive presents one compositional device while not acknowledging many others. This reduction of multiple compositional choices to one approved approach seems to betray the Guide's authors' low expectations of their audience. Instead of seeking to empower experimentation at the top end of the quality spectrum they appear to be content with helping those who struggle at the bottom. This focus might be a realistic reflection of the students' abilities and successes in a particular field or institution. One can also hope that in practice such stringent recommendations are not applied to the texts that obviously surpass the minimum quality requirements. However, persistent and ubiquitous presentation of the writing challenge from this pessimistic perspective does extend to the rest of the field, discouraging innovation from being attempted, cultivated or valued.

It might seem that the advice contained in the Guide is appropriate to the audience of students who are yet to develop their writing skills. However, by portraying writing as something distinct from the creativedesign process, it serves to perpetuate attitudes and standards that extend well beyond educational environments. Having failed to integrate writing into the core of their creative and reflective practices, students move into practice and research with a conviction that writing is an alien form of expression, unbecoming of them as "the visual people" (cf. Dunham-Jones 1997).

Furthermore, the standardising, functionalist advice is not constrained to the student audience. Many leading architectural journals also seek to constrain their writers. For example, the influential Building 
Research and Information journal states in section 2, Effective Communication, of its Instructions for Authors $^{1}$

The paper should be written and arranged in a style that is succinct and easily followed. An informative but short title, a concise abstract and keywords, and a well-written introduction will help achieve this. Simple language, short sentences and a good use of headings all help to communicate information more effectively. Discursive treatments of the subject matter are discouraged. Figures should be used to aid the clarity of the paper. The reader should be carefully guided through the paper. Always think about your reader.

Compatibly with this requirement, the journal's articles are largely technical and dry texts despite the journal's intention-evident in its Aims and Scope statement-to explore "the linkages between the built, natural, social and economic environments, with an emphasis on the interactions between theory, policy and practice $[. . .]^{\prime},{ }^{2}$ a mission that extends well beyond purely technical topics.

In some fields, the problems of academia's traditional adherence to the standards of objectivity (transparency, clarity, simplicity, detachment) are by now broadly recognized (e.g., cf. Goodall, Jr. 2000b, Richardson \& Adams St. Pierre 2000). Together with the pragmatic benefits, unification can induce monotony of form, defensive arguments, overuse of citations and boredom (cf. Richardson \& Adams St. Pierre 2000). If writing is inaccessible because it fails to relate to the experiences, interests or challenges faced by the readers or simply because it is boring, it will not be read. And it the dominant forms do not suit the disciplinary concerns, the research will not be written or even conducted.

Some topics can be the fundamental concerns of a discipline and at the same time be among the most difficult to analyse or describe. In architecture, such difficult topics include a broad spectrum of cultural, social, experiential, emotional, aesthetic and formal concerns. Sometimes the engagement with such wicked problems cannot be fit within strictly regimented, functionalist forms of representation. My intuition is that this indirect redirection of research towards reportable topics can be credited for the increasing understanding of architecture as primarily an engineering discipline. Such understanding is hardly a fair reflection of how architecture is thought of by its inhabitants and creators.

Standards and constraints supporting distinct academic research communities can undoubtedly be helpful. Indeed, the challenge of adapting to the rhetorical characteristics of a particular discipline has been described as central to academic writing (Murray \& Moore 2006: 54). This adaptation can manifest itself as a very useful exercise. It encourages academics to analyse their research profiles and develop better understandings of their disciplines. Murray and Moore (Murray \& Moore 2006: 54) suggest that this sense

\footnotetext{
${ }^{1}$ http://www.tandf.co.uk/journals/journal.asp?issn=0961-3218\&linktype $=44$

${ }^{2}$ http://www.tandf.co.uk/journals/titles/0961-3218.asp
} 
is constructed through the "understanding not only of research, but also of how research is presented in journals and, more importantly, how the case for 'contribution' to the discipline is constructed in writing". For students, junior academics or researchers extending their work into new domains, established rhetorical structures can serve as educational and time-saving templates suggesting productive ways of thinking and assisting in the construction of rigorous arguments. Together, existing forms and guidelines help the newcomers to become active participants in existing discourse communities (for the concept of discourse communities, see Swales 1990). However, as Prior (1998a) discusses in his account of literate activity in academia, disciplinary acculturation occurs as an continuous negotiation between students, professors, mentors and peers. It is not a simple case of learning the existing languages and cultures. Guides that take an authoritative stance misrepresent this process.

An increasing number of people working within academic context position their research in opposition to academic orthodoxies (cf. Kouritzin et al. 2009, Nash 2004) and there are newer journals that deliberately encourage diversity. As Zamel (1998: ix) suggests, "it is no longer possible to assume that there is one type of literacy in the academy". The acquisition of academic literacy is a form of unceasing apprenticeship that allows writers to learn about and engage with academic cultures. This process implies a development of linguistic practices but these practices in turn depend on a developed understanding of heterogeneous discourses, identities and values of the stakeholders (Lea \& Street 2006, Starfield 2007). An academic writer needs to be able to switch styles according to the task and setting, understand why he or she is doing that and what implications are likely (Creme $\&$ Lea 2008). This flexibility of adaptation depends on the existence of recognisable patterns but also practiced skills for coping with pluralism.

To clarify, this article is not arguing for the abandonment of distinguishing constraints and mechanisms by which they can be achieved. Quite the opposite, its argument is that multiple forms of writing-and the existence of standards that govern them-are beneficial.

The blurb of one manual on academic writing convincingly proclaims that "busy academics must develop productive writing practices quickly. No one has time for trial and error. To pass external tests of research output we must write to a high standard while juggling other professional tasks." (Murray 2005) This statement highlights that an ability to write quickly is important for the writing to happen at all as it competes for resources in academics' crowded schedules.

Furthermore, standardisation is useful as a very core component of a writing-process framework. Literature on all types of writing repeatedly advises that establishment of habits for writing, however contrasting from person to person, and an organisation of routines are usually essential for the writing to occur and for the projects to reach conclusions (e.g., see Murray 2005: 152, Richards \& Miller 2005: 14). These personal routines rely on the stability and longevity of discursive communities and their conventions. 
Writing - a design challenge in its own right-happens in context. As any design exercise, this writing can benefit from an imposition of constraints that focus effort and limit choices. The very process of working against a set of constraints can bring out new ideas, interpretations or forms. The very transformation of knowledge into writing - the topic of the subsequent section-is "as a consequence of having converted private thoughts into a public symbol system" (Kellogg 1994: 37), or having complied with a shared set of constraints.

Such constraints can take form of useful regulatory norms. For example, journals and other publishing venues often compete for recognition, readers, citation counts and author submissions. In this competitive environment strong, established identities are important and so can be the constraints that help to maintain them.

However, in parallel with benefits, the impetus on transparency of representation expressed in the form of universal advice can also cause serious problems. It suggests uniformity where there is none, ignores the current thinking on methodology and reporting, disregards differences in modes of learning and communication, disadvantages experimentation and creativity, functionalises and potentially discourages reading and misses opportunities to support interdisciplinary communities of practice.

Given this situation, this paper asks whether alternative conceptualizations of textual practice might 1) allow for a broader range of experimentation in research discourses; 2) encourage more radical experimentation with the means of expression; and 3) suggest more inclusive approaches to writing in education and research.

\section{DRAMA: WRITING AS A METHOD OF ENQUIRY}

Co-existent with the tradition that sees writing as representation is another trend that prioritises writing as a method of enquiry. This reconceptualization not only emphasises that writing is inextricably implicated in knowledge production but also seeks to capitalize on this dependence. This conception of writing is by now broadly accepted in some fields but is yet to attain equal recognition in architecture. Attempting to encourage a critical adoption of writing as an approach to research exploration, this section explores how such understanding of writing might impact on the forms of written expression.

For illustration, this section refers to the work of Frances Rapport because her textual production is tellingly incompatible with the recommendations discussed in the previous section. A professor in Qualitative Health Research, Rapport promotes the concept of "Performative Social Science [that] provides the research scientist with a much needed platform to move beyond traditional approaches to data collection, analysis and the presentation of study findings towards a response to research questions that closely res- 
onates with the raw materials at hand." ${ }^{33}$ (Rapport 2008) An important constituent of this stance is a desire to "encourage others to consider a range of alternative positions from which to view the world." (Rapport 2008) For example, in Narrating the Holocaust, she employs poetic representations of health to explore experiences of a concentration camp survivor. Her article argues that "these [poetic] forms can present authentic and rigorous data distillates without detracting from the emotive, contextualised and powerful messages of the original [oral testimonies]." (Rapport \& Sparkes 2009: 27) Examples that integrate poems into research analysis and representation demonstrate that poetry can be "a practical and powerful method for analysing social worlds." (Richardson 2002: 993) Poetry can achieve evocative, emotionally rich and simultaneously concise representations that involve readers differently from realist or functional prose. Exemplifying these potentials, Rapport's paper discusses the process in which extended transcripts of interviews constituting research data (of 50-60 pages each) are distilled into essential and characteristic samples of the protagonist's utterances and subsequently into research poems (of 3-4 pages). This approach helps to preserve individual idiosyncrasies of the protagonist's speech, producing, in a concise form, a close representation of the original narrative including its emotive content. Kendall and Murray (2005) observed that when encountering a poem, people are more likely to be attentive to the patterns of sound, image and ideas pertaining to a social encounter. They also can be more willing and ready to engage emotionally with such a text. In the example above, the protagonist's daughter confirmed the success of the approach to the researcher: "you have captured her story exactly ... it is as if I am listening to my mother speaking, telling her story, telling me her story [...]" (Rapport \& Sparkes 2009: 31). I include an extract below, to show how it works.

The transport lasted three weeks.

Coal wagons full of soot, no hygiene anywhere, and I was nine months pregnant.

Thirty women dying and millions of flies, dying of typhoid and I was sitting there.

We were going down the hill and the baby came out didn't move, didn't cry, and then we arrived.

We arrived in Mauthausen.

No baby clothing and three weeks in newspaper.

Americans came, Germans disappeared, no one will kill me I had to cope with that.

(Rapport \& Sparkes 2009: 32)

\footnotetext{
${ }^{3}$ My italics.
} 
The approach chosen by Rapport, while not universally applicable, is convincing in the particular research circumstances. It is an example of an established practice that differs greatly from the standardising guidelines discussed above. Those guidelines would preclude the acceptance of this approach as valid and-even more importantly-would discourage it from emerging. This returns me to the point made earlier that the guides are constraining of creativity and experimentation. In their drive towards standardisation, they promote a culture of conformism rather than that of excellence in innovation, quality or rigour.

Standardising and exclusionary practices embodied as writing guidelines continue against the background of growing appreciation of diversity in research (on ideologies and genres of academic writing, see Berkenkotter \& Huckin 1995, Threadgold 1989). As Richardson (2000: 959) insists: "the more different voices are honored within our qualitative community, the stronger-and more interesting - that community will be."

Promotion of diversity in research expression seems particularly important in architecture and design. As these fields work to develop as research communities, recognised within academia, they seek to develop shared (standardised) methods of enquiry, criteria for rigour and modes of researching. This collation of efforts and outcomes is necessary for the establishment of a coherent academic discourse. At the same time, even as these fields mature into better-defined forms, they ought to remain accepting of different ways to conduct research and able to encourage innovation. If design fields do not continue questioning the established academic approaches, they will risk abandoning what is likely to be their very competitive advantage, i.e. a "designerly" approach (cf. Cross 2006) that utilises an experimental, future-oriented attitude to learning and knowing.

Furthermore, such impetus on tolerance towards multiple modes of expression is but a fair reflection of the inherent diversity within design practice and design research (see Buchanan 1992: 5, Friedman 2000). Buchanan and Margolin (1995: xii) argue for "the value of radical systematic pluralism [...]" in design research and practice. Continuing the logic of this statement I suggest that academic expression, especially where it is understood to be integral to a research method, has to be governed and developed in ways that can support this condition of multiplicity.

In my experience, writing is never a search for one uniquely fitting harmony. Instead, it is a sequence of hesitations and unsure decisions, map-making and random jotting, pragmatic finishing of the minimally readable essentials towards deadlines and tangential musings provoked by an obscure reference. Tensions between these and other contrasting characteristics seem inherent to the writing process. For example, academic rigour requires originality while discourse communities expect compliance with conventions. Analogously, research investigations call for logic while experiential encounters depend on emotions (cf. Murray \& Moore 2006: 7 on writing as coping with paradoxes). 
Architectural representation has a tradition of coping with such tensions. It routinely incorporates collage techniques that merge multiple types of images with descriptive, proclamatory or technical texts. This tradition provides an accepting context that already experiments with multiple voices and formal innovation. However, such experimentation continues predominantly in design practice and is not compatible with currently dominant academic standards. Typically it serves promotional goals and-in today's professional climate-has also lost the radical drive for critique and social reconstruction that characterised the early $20^{\text {th }}$ century avant-garde. For this mode of expression to be valid in the research context, it needs to develop acceptable criteria for rigour and reconstitute its innovative, exploratory and critical potential.

Amongst suggestive examples provided by other traditions that experimented with seamless and radical integration of visuals, objects and texts are the templates developed within concrete poetry (Figure 1).

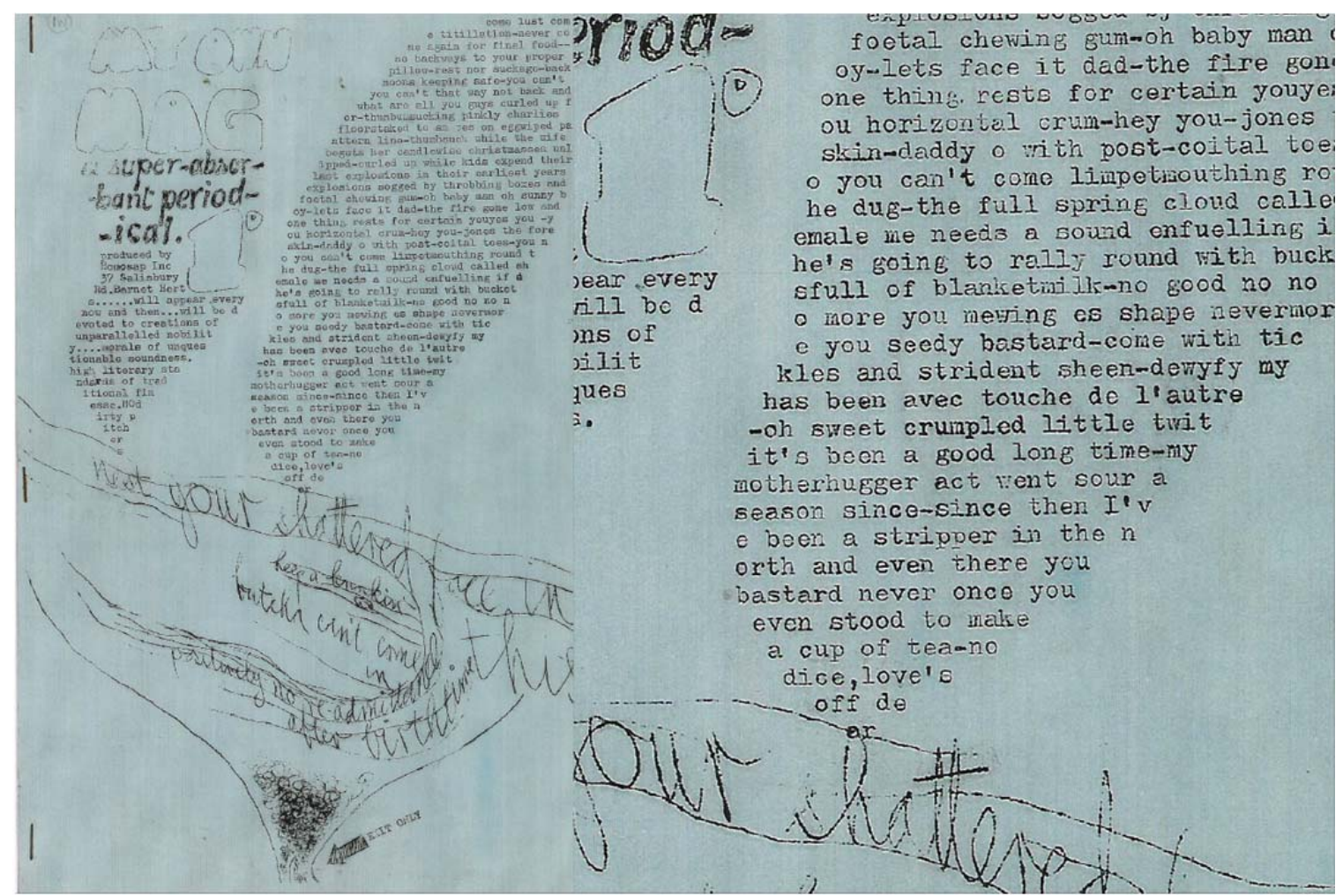

Figure 1. Jeff Nuttall. My Own Mag, issue 1, November 1963, fragments.

An in-depth discussion of the practical possibilities suggested by its approaches is outside of the scope of this article. However, below I would like to offer one example that merges the architectural context with the concrete-poetry approach achieving the results that I find suggestive in the context of this discussion. This example engages with formal textual exploration and is available in a joint publication of Pickford (1984) and Selenitsch (1984). It combines suggestive drawings and written text into a whole that incorporates several simultaneous dialogues. Pickford's drawings are presented first and present romantic and metaphoric interpretations of the central thought: the future of architecture lies in ruins. The drawings are 
accompanied by a short text that develops the idea. Selenitsch's piece that is presented on the following pages develops the theme by experimenting with the process of change and ruination through linguistic mechanisms such as addition, alteration, annotation and excision. These experiments are also framed with a textual commentary that introduces and discusses the principal idea and the formal devices in use.

THE FUTURE OFARCHITECTURE LIES IN RUINS: JASON PICKFORD

\section{CTURE LIES IN RUINS:}

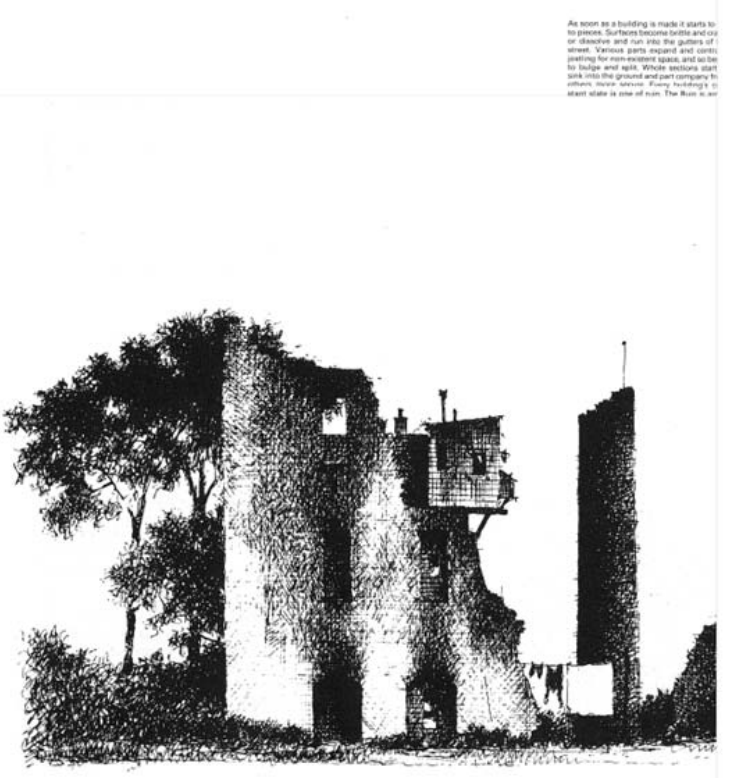

As soon as a building is made it starts to fall to pieces. Surfaces become brittle and crack. street. Various parts expand and contract jostling for non-existent space, and so begin to bulge and split. Whole sections start to
sink into the ground and part others more secure. Every building's con stant state is one of ruin. The Ruin is architecture's paradigm, an elementary model Every architect thinks his new building is the beginning of a world (however small) and
also the defeat of time. Time's ribbon stretch. ing endlessly ahead has somehow been bent into a Moebius strip. Few architects eagerly await the news of the first visible crack, the assured by this triumph of gravity The repe. tition of a natural law is usually reassuring of its naturalness and legality. Ruins should comfort us because they are assertions of
universal order - all must be right with the world if the physical laws continue to work Ruins should delight gradualists and conservatives, but radicals can take heart from the sudden collapse,

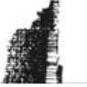

(n)

Figure 2. Pickford's article The Future of Architecture Lies in Ruins, fragments, p. 72 (Pickford 1984: 72).

Even though Pickford's and Selenitsch's textual experiment is highly idiosyncratic, it demonstrates several interesting characteristics possible through close involvement with the formal characteristics of written texts.

The publication shows how multiple voices can be integrated into one discursive gesture that does not hide the identities of the authors. The result is richer because the multiple interpretations support each other and encourage deeper reflection in the reader.

The piece employs a conversation rather than a persuasive speech as a primary mode of representation. It does not structure representation as an authoritative argument but instead presents ideas as experiments that provide textual and experiential evidence of the possibilities inherent in the content. 


\section{HERE IS A TEXT . . . ALEX SELENITCH}

and its footnote:

74. Roland Mortier, La poectique des ruines en France, Geneva, 1974, pp. 177, 201, 205. This is the best available account of the cult of ruins from the Renaissance to the nineteenth century, with special reference to France. Renzo Negri, Gusto e poessia delle rotane in Italia fra il serte e linocent, Mulan, 1965, is also valuable. The development of the idea that coincides with the emergence of new artigudes to the ress of which they were the remains 1815 Canova advised that the Elgin marbles should not be restored. In the early years of the nineteenth century the practice of removing sculprere from ancient sites also begen to arouse opposition, beginning with protests at Lord tigin's activities in Athens.

(This text was 'accidently' found while browsing, so that its discovery prompted the analogue, not the other way round as sugfrom pp. $153-4$ of ROMANTICISM by Hugh Honour, Penguin, 1981.

Note how the main paragraph is built form 2 quotes (Constant and Stendaht, out of con quotes (Constant and Stendahl, out of conan introductory pair of sentences. This ex. tract, which is a fragment of a larger book, is a conglomerate of other extracts. And as for the paragraph, so for its footnote.)

and its footr 74 Roland Mon
This is the best ava century, with speci fra il sette c l'ottoc ruins might be mol 1815 Ganova advis 1815 Canova advis
the nineteenth cen to arouse oppositio

HERE IS THE ANALOGUE

In the eighteenth century, architects quarried details from and ruins. Now they recreate (recreated?) their 'total' effect, following the writers who regard (regarded?) as objects beautiful in themselves as well as sad relics of departed worth. Chateaubriand enthused over the lichens growing on the ruins of Greece and PONDERED THE INSTITUTIONS

ie SURROUNDING HIM. CHRISTENDOM, NOW CRACKED AND SPLINTERED BY NEWTONIAN MEASUREMENT,

cc WAS ITSELF BUILT FROM THE RUINS OFROME, UNITING $A R T$ WITH ART. $(x)$ nothing, but ruins wrote Benjamin

in 1808 . went further to declare that the VIADUCT

HERE IS THE was more beautiful in his day than it had ever been.

In the eight 'These fragments of time on the soul of Cimarosa,' he wrote.

and ruins
effect, followi

was a forgery which told the truth.

HERE IS THE TEXT

Figure 3. Selenitsch's response to Pickford's article (Figure 2), fragments (Selenitsch 1984: 75).

Moving beyond the standards of clarity and simplicity, or even the constraints of the academic poetry discussed above, the piece engages with in-depth formal exploration exploring and even innovatively extending the representative capacities of language. Selenitsch's reconfigurations are interesting beyond the domain of writing because they employ compositional devices already known to architects in other contexts. The juxtaposition of the drawings and poetic reconstructions in this publication highlights such similarities and is therefore particularly suggestive.

In this publication, both the drawings and the poems are coupled with reflective pieces that-even if briefly-expose the authors' thinking, motivation and methods. This openness is empowering for the readers because, knowing the goals of the authors and their preferred interpretations, they can more readily form alternative interpretations or value judgements.

\section{CONCLUSION}

This article argues for the support and promotion of creative freedom in architectural academic writing. It suggests that compositional and stylistic choices should be motivated by requirements of particular situations rather than by generic, standardizing guidelines. Principled commitment to continuous experimentation is compatible with the heuristic methods and future-oriented disposition of designing. This experimentation needs to be supported by institutional structures including the norms that regulate students' writing or determine the format of scholarly publications. My hope is that this article can contribute to 
the realisation that adjustments towards greater plurality of research expression in architecture can be beneficial and deserve support.

How should writing guides, journal templates and other normative documents change to encourage creativity and diversity? To arrive at a convincing answer, architectural academia needs to develop a better awareness of how the outcomes of design research contribute to the field. Currently, we do not know enough about architecture as a discourse community. In other academic disciplines a number of such studies exist. For example, there are multiple evaluations of reading patterns pertaining to academic journals. These studies attempt to evaluate who reads research texts, how much time readers spend per item of reporting, how they find the reading material, how often they read it and so on (e.g., see King et al. 2006, King et al. 2009). Such studies have been conducted since the 1960s and followed the trends in linguistics moving from formal analyses to the holistic explorations considering the texts, the communities which produce them and for which they are intended as well as the situations in which the texts are produced (Bazerman \& Prior 2003, Berkenkotter \& Huckin 1995, Swales 1988). In more recent fields, such as design research, such studies are yet to take place. This article invites further work in this direction because findings of a discourse ethnography (Schrøder 2007) or a discourse analysis (Hyland 2004, Prior 1998b) could usefully contribute to a productive reconsideration of regulatory norms currently sustained by traditions largely borrowed from other disciplines.

An important consequence of the commitment to creative freedom will be in design education. Writing in other fields has already developed well-established and successful patterns for teaching through creative experimentation and sharing. Learning to write, students have to move beyond singular and prescriptive understanding of academic expression. They need to transform their understanding of writing from that of a mental activity to that of a situated one, from that of an autonomous process to that of a shared, social one, from that of writing as a formal challenge to that of an ideological one. An important model for such education is the creative-writing workshop (Canagarajah 2001, Canagarajah 2002a,b). Not unlike an architecture studio, this mode of shared learning emphasises goal-oriented experimentation in a supportive environment that encourages creativity and innovation (e.g., see Francis 2009). Extending the currently prevalent advice of writing guides and other normative instruments, creative-writing workshops can help to set ambitions higher than basic accessibility. They can foster advanced skills, encourage experimentation, help to create discourse communities and establish long-term research conversations.

\section{Contributor details}

An architect, artist and researcher, Dr Stanislav Roudavski studies and designs technologically sustained places. His current practice-based research work integrates organizational techniques of architecture, unpredictability and richness of performative situations, creative capacities of computing, visual lan- 
guages of the moving-image arts, dramaturgy and spatial narrative. He is based at the Faculty of Architecture, Building and Planning, University of Melbourne; stanislav.roudavski@cantab.net

\section{References}

Bazerman, C. \& Prior, P. A. 2003, What Writing Does and How It Does It: An Introduction to Analyzing Texts and Textual Practices, Mahwah, NJ; London: Lawrence Erlbaum.

Berkenkotter, C. \& Huckin, T. N. 1995, Genre Knowledge in Disciplinary Communication: Cognition, Culture, Power, Hillsdale, NJ; Hove: Lawrence Erlbaum.

Best, S. \& Kellner, D. 1997, The Postmodern Turn, New York; London: Guilford Press.

Bourdieu, P. 1988, Homo Academicus, orig. pub. 1984 in French as Homo academicus, Cambridge: Polity Press in association with Basil Blackwell.

Buchanan, R. 1992, 'Wicked Problems in Design Thinking', Design Issues, vol. 8, no. 2, pp. 5-21.

Buchanan, R. \& Margolin, V. (eds.) 1995, The Idea of Design, Cambridge, MA: MIT Press.

Canagarajah, A. S. 2001, 'Addressing Issues of Power and Difference in ESL Academic Writing', in Research Perspectives on English for Academic Purposes, eds. J. Flowerdew \& M. Peacock, Cambridge: Cambridge University Press, pp. 117-131.

Canagarajah, A. S. 2002a, A Geopolitics of Academic Writing, Pittsburgh: University of Pittsburgh Press.

Canagarajah, A. S. 2002b, Critical Academic Writing and Multilingual Students, Ann Arbor: University of Michigan Press.

Coyne, R. 2005, 'Wicked Problems Revisited', Design Studies, vol. 26, no. 1, pp. 5-17.

Creme, P. \& Lea, M. R. 2008, Writing at University: A Guide for Students, 3rd edn., orig. pub. 1997, Maidenhead: McGraw-Hill; Open University Press.

Cross, N. 2006, Designerly Ways of Knowing, London: Springer Verlag.

Dunham-Jones, E. 1997, 'Thoughts on Post-Fordist Production and the Star System in Architecture', Thresholds, no. 15, pp. 16-21.

Francis, P. 2009, Inspiring Writing in Art and Design: Taking a Line for a Write, Bristol; Chicago: Intellect.

Friedman, K. 2000, 'Design Knowledge: Context, Content and Continuity', in In Doctoral Education in Design. Foundations for the Future. Proceedings of the La Clusaz Conference, July 8-12, 2000, eds. D. Durling \& K. Friedman, Staffordshire University Press, Staffordshire, UK, pp. 5-16.

Goodall, H. L., Jr. 2000a, Writing Qualitative Inquiry: Self, Stories, and Academic Life, Walnut Creek, CA: Left Coast Press.

Goodall, H. L., Jr. 2000b, Writing the New Ethnography, Lanham, MD: AltaMira Press.

Hyland, K. 2004, Disciplinary Discourses: Social Interactions in Academic Writing, Michigan classics edn., orig. pub. 2000, Ann Arbor; London: University of Michigan Press. 
Kellogg, R. T. 1994, The Psychology of Writing, New York; Oxford: Oxford University Press.

Kendall, M. \& Murray, S. A. 2005, 'Tales of the Unexpected: Patients' Poetic Accounts of the Journey to a Diagnosis of Lung Cancer: A Prospective Serial Qualitative Interview Study', Qualitative Inquiry, vol. 11 , no. 5 , pp. 733-751.

Keyes, R. 2003, The Courage to Write: How Writers Transcend Fear, 2nd edn., orig. pub. 1995, New York: H. Holt.

King, D. W., Tenopir, C. \& Clarke, M. 2006, 'Measuring Total Readings of Journal Articles', D-Lib Magazine, vol. 10 , no. 12 .

King, D. W., Tenopir, C., Choemprayong, S. \& Wu, L. 2009, 'Scholarly Journal Information Seeking and Reading Patterns of Faculty at Five U.S. Universities', Learned Publishing, vol. 22, no. 2, pp. 126 144.

Kouritzin, S. G., Piquemal, N. A. C. \& Norman, R. (eds.) 2009, Qualitative Research: Challenging the Orthodoxies in Standard Academic Discourse(s), New York: Routledge.

Lakoff, G. \& Johnson, M. 1980, Metaphors We Live By, Chicago: University of Chicago Press.

Latour, B. 1987, Science in Action: How to Follow Scientist and Engineers through Society, Cambridge, MA: Harvard University Press.

Latour, B. \& Woolgar, S. 1992, Laboratory Life: The Construction of Scientific Facts, orig. pub. 1979, Princeton: Princeton University Press.

Lea, M. R. \& Street, B. V. 2006, 'Student Writing in Higher Education: An Academic Literacies Approach', Studies in Higher Education, vol. 23, no. 2, pp. 157-172.

Lincoln, Y. S. \& Denzin, N. K. 2003, Turning Points in Qualitative Research: Tying Knots in a Handkerchief, Walnut Creek, CA; Oxfor: AltaMira Press.

Luey, B. 2010, Handbook for Academic Authors, 5th edn., orig. pub. 1987, Cambridge: Cambridge University Press.

Murray, R. 2005, Writing for Academic Journals, Maidenhead: Open University Press.

Murray, R. \& Moore, S. 2006, The Handbook of Academic Writing: A Fresh Approach, Maidenhead: Open University Press.

Nabokov, V. 2000, Speak, Memory: An Autobiography Revisited, orig. pub. 1966 as Conclusive Evidence, London: Penguin Classics.

Nash, R. J. 2004, Liberating Scholarly Writing: The Power of Personal Narrative, New York; London: Teachers College Press.

Pickford, J. 1984, 'The Future of Architecture Lies in Ruins', Transition: Discourse on Architecture, vol. 3, no. 3, 4, pp. 72-74.

Prior, P. A. 1998a, Writing/Disciplinarity: A Sociohistoric Account of Literate Activity in the Academy, Mahwah, NJ; London: Lawrence Erlbaum. 
Prior, P. A. 1998b, Writing/Disciplinarity: A Sociohistoric Account of Literate Activity in the Academy, Mahwah, NJ; London: Lawrence Erlbaum.

Rapport, F. (2009/11/04), The Poetry of Holocaust Survivor Testimony: Towards a New Performative Social Science, [Online], Available from: <http://nbn-resolving.de/urn:nbn:de:0114-fqs0802285>.

Rapport, F. \& Sparkes, A. C. 2009, 'Narrating the Holocaust: In Pursuit of Poetic Representations of Health', Journal of Medical Ethics; Medical Humanities, no. 35, pp. 27-34.

Richards, J. C. \& Miller, S. K. 2005, Doing Academic Writing in Education: Connecting the Personal and the Professional, Mahwah, NJ: Lawrence Erlbaum.

Richardson, J. 2007, A Life of Picasso: The Triumphant Years, 1917-1932, London: Jonathan Cape.

Richardson, L. 2002, 'Poetic Representation of Interviews', in , London: Sage, pp. 877-892.

Richardson, L. \& Adams St. Pierre, E. 2000, 'Writing: A Method of Enquiry', in Handbook of Qualitative Research, eds. N. K. Denzin \& Y. S. Lincoln, Thousand Oaks,CA: Sage, pp. 923-948.

Rorty, R. 1989, Contingency, Irony, and Solidarity, Cambridge: Cambridge University Press.

Schrøder, K. C. 2007, 'Media Discourse Analysis: Researching Cultural Meanings from Inception to Reception', Textual Cultures: Texts, Contexts, Interpretation, vol. 2, no. 2, pp. 61-76.

Selenitsch, A. 1984, 'Here is a Text', Transition: Discourse on Architecture, vol. 3, no. 3, 4, pp. 72-74.

Starfield, S. 2007, 'New Directions in Student Academic Writing', in The International Handbook of English Language Teaching, eds. J. Cummins \& C. Davidson, Norwell, MA: Springer, pp. 875-890.

Strunk, W., Jr. 2000, The Elements of Style, 4th edn., orig. pub. 1918, New York: Longman.

Swales, J. M. 1988, 'Discourse Communities, Genres and English as an International Language', World Englishes, vol. 7, no. 2, pp. 211-220.

Swales, J. M. 1990, Genre Analysis: English in Academic and Research Settings, Cambridge: Cambridge University Press.

Threadgold, T. 1989, 'Talking about Genre: Ideologies and Incompatible Discourses', Cultural Studies, vol. 3, no. 1, pp. 101-127.

University of Melbourne, Faculty of Architecture Building and Planning \& Miles, L. (2009/11/16), Essay and Report Writing, [Online], Available from: <http://www.abp.unimelb.edu.au/environmentsand-design-students/pdf/essay-guide.pdf>.

Williams, J. M. 2002, Style: Ten Lessons in Clarity and Grace, 7th edn., orig. pub. 1981, New York; Harlow: Longman.

Zamel, V. \& Spack, R. 1998, Negotiating Academic Literacies: Teaching and Learning across Languages and Cultures, Mahwah, NJ; London: Lawrence Erlbaum. 


\section{University Library}

\section{- M M I N E R VA A gateway to Melbourne's research publications}

Minerva Access is the Institutional Repository of The University of Melbourne

Author/s:

Roudavski, S

Title:

Transparency or drama? Extending the range of academic writing in architecture and design

Date:

2010-12-01

Citation:

Roudavski, S. (2010). Transparency or drama? Extending the range of academic writing in architecture and design. Journal of Writing in Creative Practice, 3 (2), pp.111-133. https:// doi.org/10.1386/jwcp.3.2.111_1.

Publication Status:

Published

Persistent Link:

http://hdl.handle.net/11343/28965 